\title{
Laser and radiofrequency-induced hyperthermia treatment via gold-coated magnetic nanocomposites
}

This article was published in the following Dove Press journal:

International Journal of Nanomedicine

27 September 2011

Number of times this article has been viewed

\author{
Alsayed AM Elsherbini' \\ Mahmoud Saber ${ }^{2}$ \\ Mohamed Aggag ${ }^{2}$ \\ Ahmed El-Shahawy ${ }^{2}$ \\ Hesham AA Shokier ${ }^{1}$ \\ 'National Institute of Laser Enhanced \\ Science, ${ }^{2}$ Children's Cancer Hospital, \\ Cairo, Egypt
}

Introduction: The current radiofrequency ablation technique requires invasive needle placement. On the other hand, most of the common photothermal therapeutic methods are limited by lack of accuracy of targeting. Gold and magnetic nanoparticles offer the potential to heat tumor tissue selectively at the cellular level by noninvasive interaction with laser and radiofrequency.

Methods: Gold nanospheres and gold-coated magnetic nanocomposites were used for inducing hyperthermia to treat subcutaneous Ehrlich carcinoma implanted in female mice.

Results: In mice treated with gold nanospheres, tumors continued to grow but at a slow rate. In contrast, more than $50 \%$ of the tumors treated with gold-coated magnetic nanocomposites completely disappeared.

Conclusion: This simple and noninvasive method shows great promise as a technique for selective magnetic photothermal treatment.

Keywords: laser, hyperthermia, gold magnetic nanocomposites, Ehrlich carcinoma

\section{Introduction}

Hyperthermia is under consideration currently as a noninvasive approach to cancer therapy, whereby biological tissues are exposed to higher than normal temperatures to promote selective destruction of abnormal cells. ${ }^{1}$ In the mid 1970s, growing interest in conventional hyperthermia as a cancer treatment modality led to the development of techniques such as whole body hyperthermia, local body hyperthermia, and regional hyperthermia. These modalities were developed for oncology applications and investigation of the efficacy of hyperthermia in cancer treatment. ${ }^{2}$ The available hyperthermic techniques for cancer therapy have low spatial selectivity in heating of tumors and surrounding healthy tissue. ${ }^{3}$

The emergence of nanotechnology and nanoscience has led to the development and investigation of metallic nanostructure surfaces or materials for biomedical applications. Various nanotechnologies have been investigated for phototherapy, including magnetite nanoparticles, titanium oxide nanoparticles, and illumination with ultraviolet A irradiation. ${ }^{4}$ Metallic nanostructures, such as half nanoshells (ie, nanospheres coated with silver), have previously been developed as a platform for surface-enhanced Raman scattering detection in gene diagnostics and cellular imaging ${ }^{5}$ using surfaceenhanced Raman scattering. One of the ways to improve laser spatial heating selectivity is photothermal labeling of tumor tissue by gold nanoparticles with different shapes and structures, such as nanoshells, ${ }^{6}$ nanorods, ${ }^{7}$ nanocages,${ }^{8}$ and others.., 10 By exposing nanoparticles to laser radiation near their plasmon-resonant absorption
Correspondence: Alsayed AM Elsherbini National Institute of Laser Enhanced Science, Cairo University, Egypt, PO Box 12613, Cairo, Egypt

Tel +202 5729499

Fax +202 5729499

Email elsayed@niles.edu.eg 
band, it is possible to produce local heating of nanoparticlelabeled cells without harming surrounding healthy tissues. Such an approach has been developed over the last 5 years and is known as plasmonic photothermal therapy. ${ }^{11}$

Gold nanoshells belong to a prospective class of optical adjustable nanoparticles with a dielectric silica core encased in a thin metallic gold shell. ${ }^{12}$ The absorption cross-section of a solid nanoshell is high enough to provide a competitive nanoparticle technology with application of indocyanine green dye, a typical photothermal sensitizer used in laser cancer therapy. ${ }^{13,14}$ There are several papers on in vitro experiments using gold nanoparticles in plasmonic photothermal therapy for cancer cells, but in vivo and ex vivo studies are quite limited. ${ }^{15}$ There remain several areas to be studied more thoroughly. First of all, there is the question of controlled and localized hyperthermia without significant overheating of both the tumor and surrounding normal tissues. Precise control over local temperature distribution is the key factor to be considered in the context of enhanced plasmonic photothermal therapy efficacy. Laser heating can result in tumor necrosis, apoptosis, and accelerated tumor growth, depending on the accuracy of heating and rise in tumor temperature on illumination with laser light. Specifically, heating up to $39^{\circ} \mathrm{C}-45^{\circ} \mathrm{C}$ may lead to acceleration of biological reactions accompanied by production of heat shock proteins and vigorous growth of the tumor. ${ }^{16-18}$ This study evaluated two different approaches in the nanotechnology era for inducing hyperthermia in subcutaneous Ehrlich carcinoma cells.

\section{Materials and methods}

All chemicals used in this study were analytical grade reagents and used without further purification. Preparation of $5 \times 10^{3} \mathrm{~mol} / \mathrm{L}$ of gold nanospheres was accomplished using the citrate reduction route in the following manner. In brief, $\mathrm{HAuCl}_{4} 0.1699 \mathrm{~g}$ was added to $100 \mathrm{~mL}$ of double-distilled water, producing a faint yellowish solution; $5 \mathrm{~mL}$ of this solution was then added to $90 \mathrm{~mL}$ of double-distilled water. The solution was heated until boiling point, and $5 \mathrm{~mL}$ of $0.5 \%$ sodium citrate was added to the boiling solution with vigorous magnetic stirring. Heating was continued for another 15 minutes until the color of the solution gradually changed to a wine-red color. The solution was made up to $100 \mathrm{~mL}$ using double-distilled water, stirred for a further 15 minutes, and then stored at $4^{\circ} \mathrm{C}$.

\section{Preparation of nanocomposites}

Firstly, magnetic nanoparticles were prepared according to the method described by Elsherbini et al. ${ }^{19}$ The gold-coated magnetic nanoparticles were prepared as follows. A $0.01 \mathrm{mg}$ aliquot of the prepared magnetic nanoparticles was suspended in $25 \mathrm{~mL}$ of glycerol. The suspension was shaken vigorously on the magnetic stirrer and heated to approximately $200^{\circ} \mathrm{C}$. The solution of gold salt $\left(5 \mathrm{~mL}\right.$ of $\left.5 \times 10^{3} \mathrm{~mol} / \mathrm{L}\right)$ was then added dropwise. The color of the mixture changed from darkbrown to deep-red. Heating was continued with stirring for other 15 minutes. The $\mathrm{AuFe}_{3} \mathrm{O}_{4}$ nanoparticles were purified several times by adding $100 \mathrm{~mL}$ of absolute ethanol, and then dried at $60^{\circ} \mathrm{C}$ and stored at $4^{\circ} \mathrm{C}$.

\section{Preparation of tumor-bearing mice}

Female 6-8-week-old Swiss albino mice (20.0-29.2 g, median $26.3 \mathrm{~g}$ ) from the breeding unit of the Egyptian National Cancer Institute were subcutaneously inoculated with $1 \times 10^{6}$ Ehrlich carcinoma cells $/ \mathrm{mL}$ to obtain a single grafted tumor. Ehrlich carcinoma cells were implanted in all mice on the same day and under the same conditions. During implantation, the mice were anesthetized using fentanyl dihydrochloride (Janssen Cilag, Neuss, Germany) $50 \mathrm{mg} / \mathrm{kg}$ body weight. The tumors started to appear within 7 days of implantation. Twenty days following implantation, tumor volumes for all mice were measured using calipers in three orthogonal diameters $\left(D_{1}, D_{2}\right.$, and $\mathrm{D}_{3}$, see Supplementary Figure 1).

$$
\text { Tumor volume }=\left(\mathrm{D}_{1} \mathrm{D}_{2} \mathrm{D}_{3}\right)(\pi / 6)
$$

\section{Characterization instruments}

Transmission electron microscopy of the prepared samples was performed by drying a drop of the solution on a carboncoated copper grid. Particle sizes were determined from micrographs taken using a Joel-100S transmission electron microscope with a resolution of $0.3 \mathrm{~nm}$. An X-ray diffraction analysis crystallographic study was performed on the nanocomposite powder using a rotating anode X-ray diffractometer (Rigaku, Tokyo, Japan) with $\mathrm{Cu}$ Ka radiation. Spectroscopic characterization of the colloidal solution of gold nanospheres and core shell nanoparticles was undertaken using an ultraviolet-visible spectrophotometer (Lambda 40, Perkin-Elmer, Redmond, WA) with a matched quartz cell and a path length of $1 \mathrm{~cm}$.

\section{In vivo laser experiments}

The experiments started 4 weeks following tumor implantation when a grossly visible and palpable mass of tumor tissue was present. Tumor volume measurements showed that the initial mean tumor volume was $74.8 \pm 1.3 \mathrm{~mm}^{3}$. The mice were allocated to four groups containing equal numbers of mice $(\mathrm{n}=25)$, ie, group I (control), group II (phosphate-buffered 
saline), group III (gold nanospheres), and group IV (gold-coated magnetic $\left[\mathrm{Au} @ \mathrm{Fe}_{3} \mathrm{O}_{4}\right]$ nanoparticles). The experiments were done in the following sequence.

The skin at the tumor site was swabbed with polyethylene glycol (PEG) as an index matching agent to maximize penetration of light into the tissue, and PEG-passivated green, a near infrared laser-absorbing agent. The group I (control) mice did not receive injections or laser exposure. All mice in group II were injected with $15 \mu \mathrm{L}$ of $10 \mathrm{mM}$ phosphatebuffered saline, and mice in group III and group IV were injected with $100 \mu \mathrm{L}$ of gold nanospheres and $\mathrm{Au} @ \mathrm{Fe}_{3} \mathrm{O}_{4}$ nanoparticles, respectively. The injected volume of all solutions was fixed at $1.0 \mathrm{~mL}$. All nanoparticles were administered via direct injection into the tumor interstitium at a rate of approximately $1 \mathrm{~mL}$ at 3-minute intervals. The mice were anesthetized with isoflurane via a face mask after a time interval of approximately 30-60 minutes from starting the injection. This time was sufficient to allow the nanoparticles to accumulate in the tumor tissue, and then the laser exposures were started. All tumors in group II and group III were extracorporeally exposed to superficial green laser light with the same parameters (CW $\lambda 535 \mathrm{~nm}$, power $0.5-1.0 \mathrm{~W}$, laser fluency $200 \mathrm{~J} / \mathrm{cm}^{2}$, and duration 15-30 minutes) as shown in Figure 1, while tumors in group IV were injected with core shell nanoparticles and exposed to green diode laser superficially with the same parameters and interstitially exposed to near infrared light $\left(\mathrm{CW}, \lambda 980 \mathrm{~nm}\right.$, power $\left.1 \mathrm{~W} / \mathrm{cm}^{2}\right)$ simultaneously, as shown in Figure 1.

Temperature changes inside the tumor were recorded using a hand-held digital thermometer (Model 100, Barnant Company, Barrington, IL). For recording of interstitial temperature, a copper-constantan thermocouple was inserted and fixed into the tumor $2-3 \mathrm{~mm}$ below the surface. The tip of the

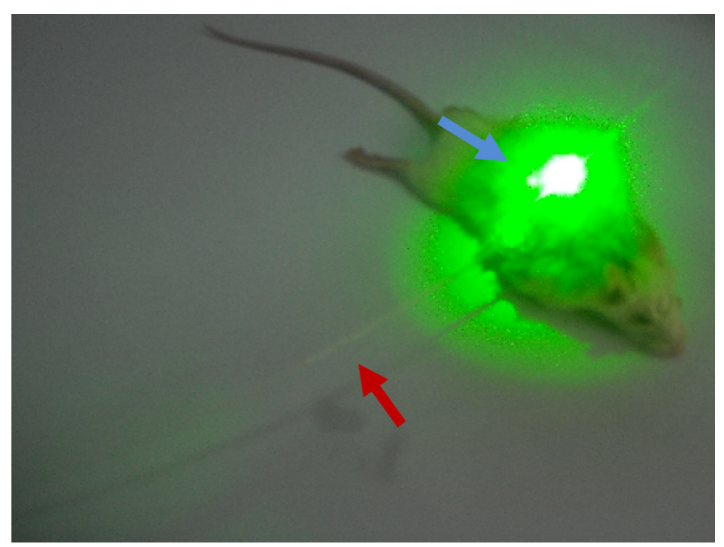

Figure I Mouse with Ehrlich tumor under experiment. Two different laser sources: the blue arrow refers to the superficial green diode laser in the visible region, while the red arrow refers to the interstitial red diode laser in the NIR region. thermostat was inserted into the injection site through a small incision, followed by exposure to laser light. Temperatures at the injection site were then recorded at 3-minute intervals prior to, during, and following exposure to laser light. The experiments were repeated at 5-day intervals for 30 days following the start of treatment (Supplementary Figure 2).

\section{In vivo radiofrequency experiments}

One hour after laser exposure, the group IV mice were positioned inside the magnetic field and subjected to radiofrequency for magnetic resonance imaging and treatment at the same time. The radiofrequency experiment was done as follows. The mice were anesthetized with isoflurane $2 \%-3 \%$ via face mask induction through a mobile inhalation system (DRE Inc, Louisville, KY). To focus the radiofrequency on the region of interest, a surface transmit and receive radiofrequency induction coil (inner diameter $7 \mathrm{~cm}$, length $7 \mathrm{~cm}$ ) specially designed for small animal imaging, was placed in the center of the tumor area in all experiments (Supplementary Figure 3). All imaging studies were performed in the Department of Radiology at the Children's Cancer Hospital, using a 1.5 Tesla high-field magnetic resonance scanner (Magnetom, Espree, Siemens, German) equipped with high-performance gradients $(23 \mathrm{mT} / \mathrm{m}$ maximum amplitude $120 \mathrm{~T} / \mathrm{m} / \mathrm{sec})$ and fast receiver hardware (bandwidth $\pm 500 \mathrm{mHz}$ ). The imaging parameters were optimized for all experiments as follows: slice thickness $2 \mathrm{~mm}$, interspaces $1 \mathrm{~mm}$, field of view $160 \mathrm{~mm}$, average 15 , matrix $256 \times 256,12$ slices per acquisition, power $25 \mathrm{~kW}$, duty $100 \%$, and bandwidth $9.62 \mathrm{kHz}$. The only variable factor was the duration of exposure, which was limited to $30-40$ minutes. All mice in group IV were subjected to radiofrequency before and 15 minutes after localized injection of nanocomposites, which were injected directly into the central portion of the tumors over a 5-minute period.

\section{Assessment of treatment response}

The response of the tumor and overlying skin was monitored daily during treatment for 30 days. The changes that occurred in the tumors are described according to their shape and treatment period (3-6 days, 10-15 days, 15-20 days, and 21-30 days). Following the treatment sessions, samples of control tumors and those treated with nanocomposites were fixed in a $1 \%$ glutaraldehyde $+4 \%$ formaldehyde mixture in $0.1 \mathrm{M}$ phosphate buffer, $\mathrm{pH} 7.2$, followed 1 hour later by post-fixing in $1 \%$ osmium tetroxide. After washing with distilled water for 30 minutes, the tissue was stained en bloc with $2 \%$ uranyl acetate and lead citrate for 30 minutes at $60^{\circ} \mathrm{C}$. The cells were 
then rinsed again in three changes of distilled water, dehydrated in progressively higher concentrations of ethanol and 100\% propylene oxide, and embedded in resin. Thin (90 nm) sections were cut on a Reichert Ultracut E ultramicrotome, placed on 200 mesh copper grids, stained with lead citrate, and examined using a Philips CM100 transmission electron microscope. Pictures were captured using a charge-coupled device camera from Image Processing Systems GmbH (Gaunting, Germany) operating at $120 \mathrm{kV}$. The necrotic area in each specimen was analyzed morphometrically using image processing software (NIH Scion Image, Frederick, MD). The percentage of necrosis in proportion to the tumor area was calculated as:

$$
\text { Percentage of necrosis }=100[n /(n+t)]
$$

where $(n)$ represents necrotic area and $(t)$ represents tumor cell area. All pathological studies were done at the Children's Cancer Hospital, and all slides were assessed by a certified pathologist.

This study also assessed response to treatment by monitoring tumor growth rates, measuring changes in tumor volume before and after hyperthermia treatment, and the relative tumor volumes with respect to the control tumors. Ellipsoidal tumor volumes were measured following treatment. The tumor volume changes were scheduled and presented as the mean \pm standard deviation, and are shown both in table form and as graphical representations in the form of growth curves for both the experimental and control groups.

All mice were housed in similar environmental conditions and received the same diet. The number of mice surviving 80 days in groups II, III, and IV were considered to be an indicator of treatment efficacy. The number of dead mice were recorded at 10-day intervals, with the pattern of mortality shown as the decrease in numbers of surviving mice during the follow-up period.

\section{Statistical analysis}

Statistical analysis was performed by comparing mean tumor sizes at day 0 and day 30 post-treatment and computing the level of significant difference as measured by the $P$ value. Similarly, $P$ values were computed to compare mean interstitial temperatures for groups treated with phosphate-buffered saline, gold nanospheres, and core shell nanoparticles. $P$ values less than 0.05 were considered to be statistically significant, and less than 0.001 was considered to be very statistically significant. Statistical analysis of the area of necrosis was done using Student's $t$-test with SPSS statistical package (v 12; SPSS Inc, Chicago, IL).

\section{Results \\ Characterization of gold nanospheres and nanocomposites}

The ultraviolet-visible absorption spectra and transmission electron micrographs shown in Figure 2A demonstrate a peak, with maximum absorption centered at a $\lambda$ of approximately $520 \mathrm{~nm}$, corresponding to gold nanospheres. The core shell peak is broader than that of the gold nanospheres and centered at a $\lambda$ of approximately $537 \mathrm{~nm}$ (Figure 2B).

Transmission electron microscopy of the gold nanospheres shows that the size was about $15 \pm 1.5 \mathrm{~nm}$. On the other hand, transmission electron microscopy of the prepared $\mathrm{Au} @ \mathrm{Fe}_{3} \mathrm{O}_{4}$ core shell nanoparticles shows approximately spherical shapes with different sizes of about $54 \pm 3 \mathrm{~nm}$ as well as superparamagnetic iron oxide nanoparticles $\left(\mathrm{Fe}_{3} \mathrm{O}_{4}\right)$ showing spherical shapes, with sizes in the approximate range of 22-55 $\mathrm{nm}$ (Figures $3 \mathrm{~A}$ and B).

The X-ray diffraction spectra of the superparamagnetic iron oxide $\left(\mathrm{Fe}_{3} \mathrm{O}_{4}\right)$ nanoparticles and $\mathrm{Au} @ \mathrm{Fe}_{3} \mathrm{O}_{4}$ core shell nanoparticles revealed characteristic diffraction peaks of $\mathrm{Fe}_{3} \mathrm{O}_{4}$ marked by their indices of $220,311,400,422,511$, and 400 (at $2 \theta$ of $30.1^{\circ}, 35.5^{\circ}, 43.1^{\circ}, 53.4^{\circ}, 57.0^{\circ}, 62.6^{\circ}$, and $75.1^{\circ}$, respectively), while the characteristic diffraction peaks of gold are marked by their indices of 111, 200, 220, and 310 (at $2 \theta$ of $38.20^{\circ}, 45.10^{\circ}, 65^{\circ}$, and $78.1^{\circ}$, respectively, Figure 3).

\section{Temperature measurements}

Interstitial temperatures were measured during each laser treatment method over the treatment sessions for all mice in

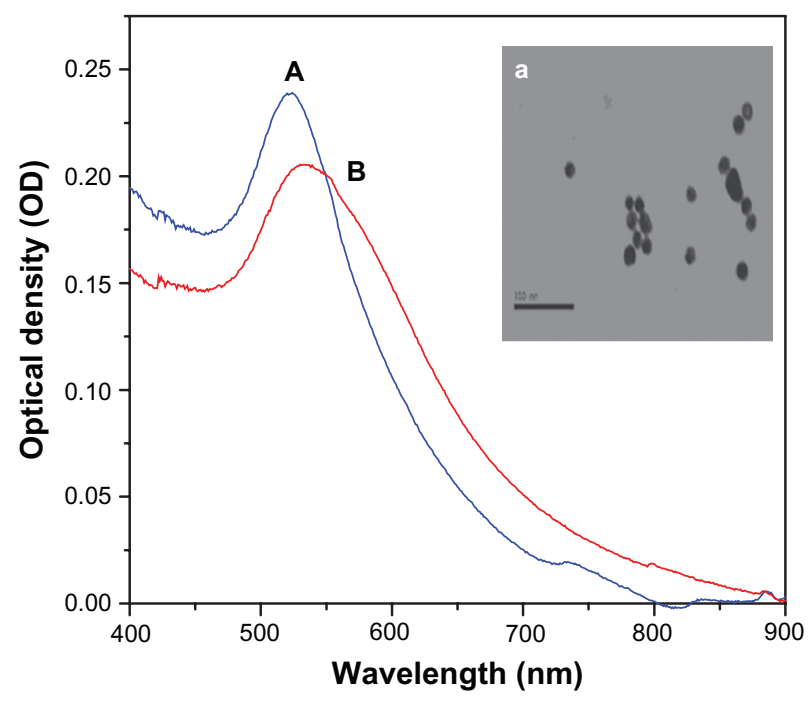

Figure 2 UV-Vis absorption spectra of (A) gold nanosphere and (B) $\mathrm{Au} @ \mathrm{Fe}_{3} \mathrm{O}_{4}$ core-shell nanocomposites. Inset: transmission electron microscope image of gold nanosphere. 


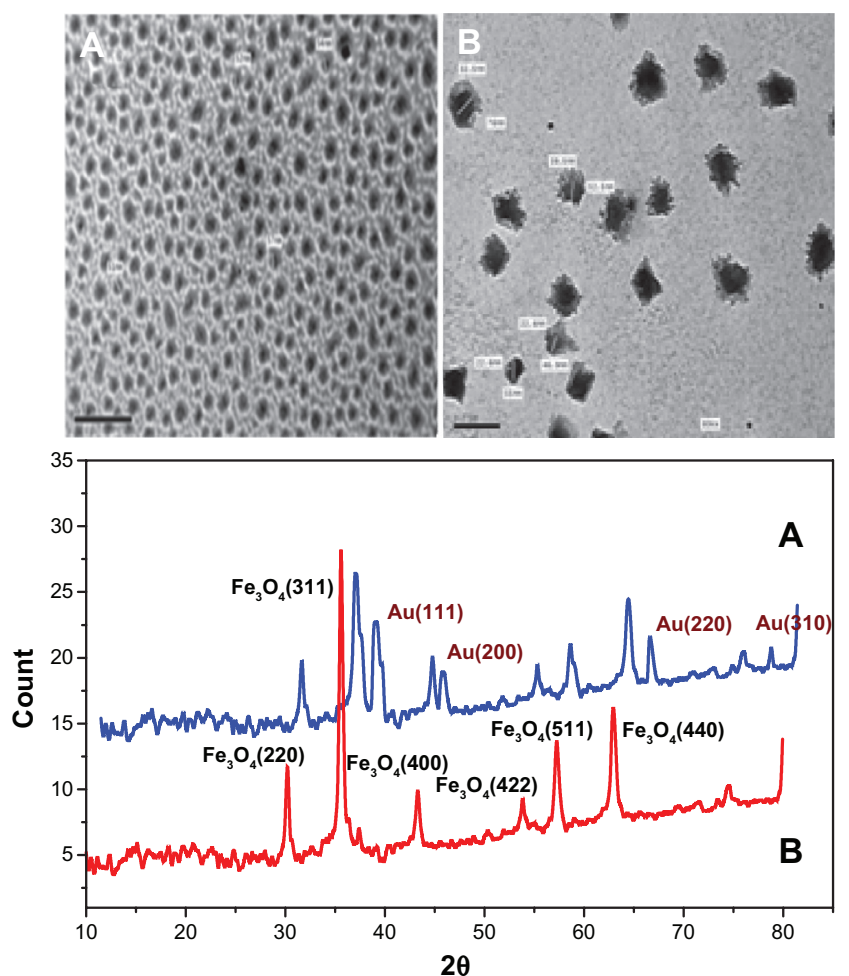

Figure 3 TEM images and XRD patterns of (A) SPIO nanoparticles $\left(\mathrm{Fe}_{3} \mathrm{O}_{4}\right)$, and (B) $\mathrm{Au} @ \mathrm{Fe}_{3} \mathrm{O}_{4}$ core-shell nanocomposites.

Note: The red line represents XRD of SPIO (A), while the blue line represents the core shell (B).

Abbreviations: TEM, transmission electron microscopy; XRD, X-ray diffraction; SPIO, super paramagnetic iron oxide.

group II (phosphate-buffered saline), group III (gold nanospheres), and group IV (core shell nanoparticles). The mean initial temperature inside the tumors was $26.1^{\circ} \mathrm{C} \pm 1.2^{\circ} \mathrm{C}$ for all mice. Under laser irradiation, interstitial temperatures increased with time until a maximum temperature was achieved. The minimum and maximum temperatures were $30^{\circ} \mathrm{C}-34^{\circ} \mathrm{C} \pm 2.5^{\circ} \mathrm{C}$ for group II (phosphate-buffered saline), $45^{\circ} \mathrm{C}-48^{\circ} \mathrm{C} \pm 1.5^{\circ} \mathrm{C}$ for group III (gold nanospheres), and $48^{\circ} \mathrm{C}-50^{\circ} \mathrm{C} \pm 1.5^{\circ} \mathrm{C}$ for group IV (core shell nanoparticles). The mean time taken to maximum temperature was (12 \pm 3 minutes, $9 \pm 2$ minutes, and $5 \pm 1$ minutes, respectively, Figure 4).

\section{Macroscopic changes}

Some morphological changes appeared on the tumor surfaces on different treatment days. Within 3-6 days of starting treatment, a black discoloration indicating necrosis appeared on the tumor surfaces. Within 10-15 days of repeating the treatment, this black discoloration turned into a crust covering an ulcer. The dimensions of these ulcers were small and varied considerably between the groups, being deeper and larger in group III (gold nanospheres) and group IV (core shells) than

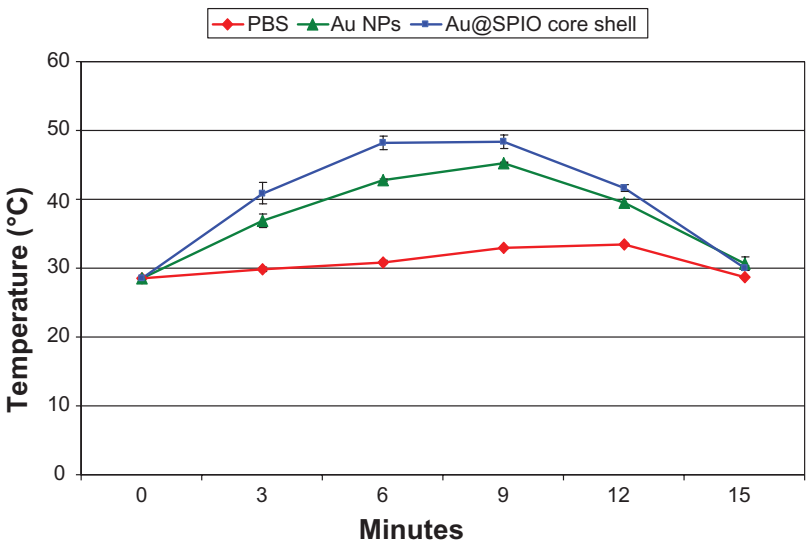

Figure 4 Mean of thermal transient measurements of Ehrlich tumor interstitial during plasmonic photo thermal treatment, using direct injection of Au nanospheres, I mL 0.9\% PBS and core shell $\left(\mathrm{Au} @ \mathrm{Fe}_{3} \mathrm{O}_{4}\right)$.

Note: Data reported represents the mean values along the treatment sessions; errors reported as standard deviation.

Abbreviations: PBS, phosphate buffer saline; Au, gold.

in group II (phosphate-buffered saline). After 15-20 days of treatment, the crusting covered the entire surface of the tumor. By day 21-30 of the experiment, the tumors had a cauliflower appearance with separation of the crusts, showing that some of the ulcers had started to heal (see Supplementary Figure 4). Separation of the crusts left hairless areas on the backs of the mice that were covered again with a yellowish crust. Only about $10 \%$ of mice in group II (phosphate-buffered saline) had these findings compared with $90 \%$ of mice in group II (gold nanospheres) and group IV (core shells). In contrast with mice in group III (gold nanospheres), most of the mice treated with the nanocomposites showed a marked reduction in tumor depth (see Supplementary Figure 1).

\section{Microscopic changes}

After six treatment sessions, pathological findings in all specimens from mice treated with gold nanospheres and nanocomposites showed widespread tumor cell disaggregation coupled with more nuclear hyperchromatism, cytoplasmic retraction, cell fragmentation, and loss of normal tissue architecture and membrane integrity, as well as infiltration and inflammatory cells, revealing different degrees of necrosis. Transmission electron micrographs were acquired from the control tumors and tumors treated with core shell nanoparticles only. In the control samples, there were no pathological changes (Figure 5A). Figure 5B shows two daughter cells immediately taking up the injected core shell nanoparticles. Nearly all nanoparticles visible are outside the cells and aggregated within the extracellular spaces (marked arrows). Figure 5C shows evidence of uptake of nanoparticles inside the cell by endocytosis after a time delay of 

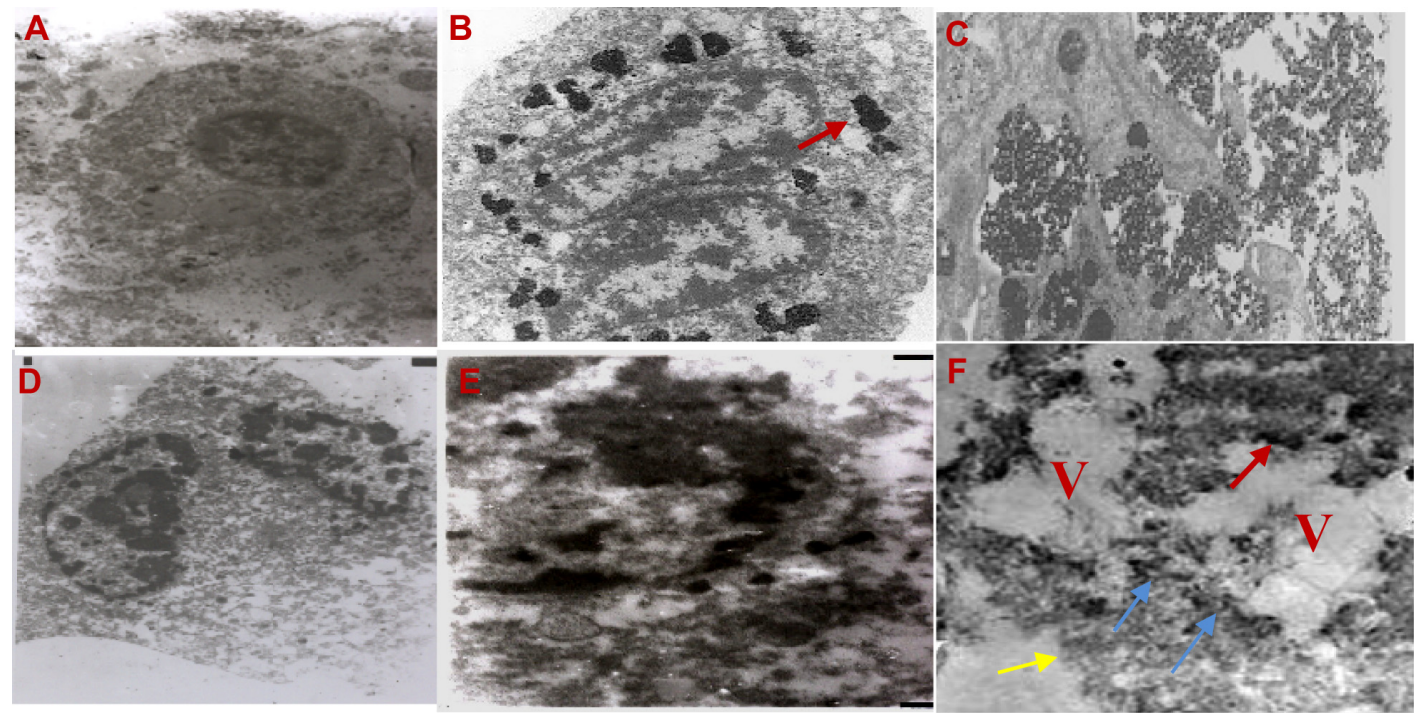

Figure 5 Transmission electron microscope pictures $(2.4 \mu \mathrm{m})$ of subcutaneous EAC $(\mathbf{A})$ control, $(\mathbf{B}$ and $\mathbf{C})$ after injection by core shell NPs and $(\mathbf{D}-\mathbf{G})$ after $($ laser + RF irradiation) one, three, and six sessions of treatments, respectively.

Abbreviations: EAC, Ehrlich ascites carcinoma; NPs, nanoparticles; RF, radio frequency.

about 1 hour, indicating phagosomes containing significant numbers of nanoparticles. Figure 5D shows deformation of the cell membrane after the first treatment session. After three sessions of treatment, some cellular changes were evident on transmission electron microscopy, as shown in Figure 5E, which reveals that the cytoplasm is more condensed, with partial detachment of the cell membrane and disappearance of all morphological features when compared with controls. Transmission electron microscopy at the end of the treatment sessions showed similar signs of cell damage in tumors treated with core shell nanoparticles and gold nanospheres,

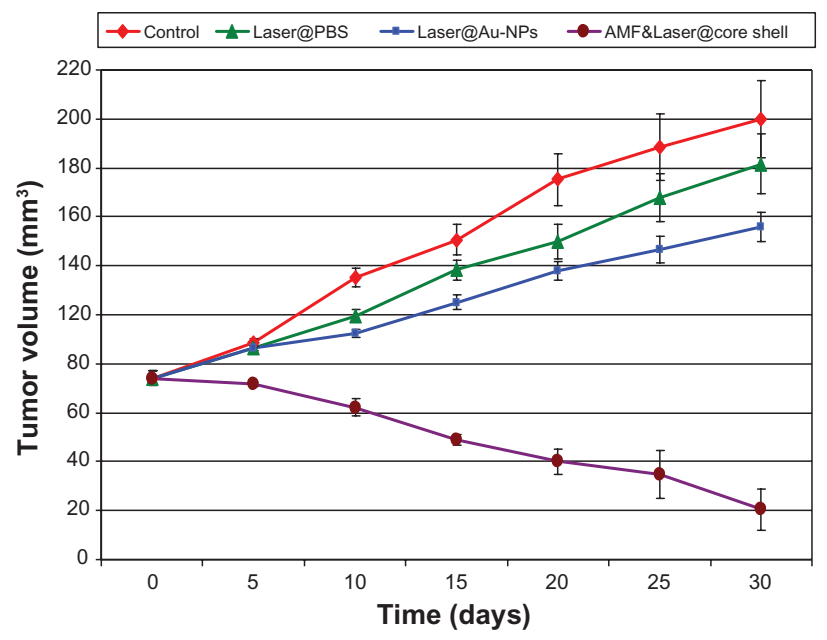

Figure 6 Efficacy of photo thermal therapy of the groups (laser@PBS, laser@AuNPs and core shell treated one against control).

Note: Data reported in the Figure represents the mean values along the treatment sessions.

Abbreviations: PBS, phosphate buffer saline; AuNPs, gold nanospheres. with the cytoplasm containing large vacuoles, destruction of the cell membrane (yellow arrows), and cytoplasm spilling out into extracellular space. Adjacent to the cell, there are unstructured necrotic structures (blue arrows) which may be the remains of destroyed cells, as well as evidence of the core shell nanoparticles (red arrows, Figure 5D).

\section{Tumor volume measurements}

Changes in tumor volume were measured at 5-day intervals for 30 days and are presented as the mean \pm standard deviation for groups I, II, III, and IV from the day of starting treatment (day 0 , volume $74.8 \pm 1.3 \mathrm{~mm}^{3}$ ). The mean change in tumor volume for each group is reported in Table 1.

Quantitative analysis of the tumor volumes for the 25 mice in each group is presented in Figure 6, showing a delay in mean tumor growth for all mice subjected to green diode laser and treated with gold nanospheres compared with tumor growth in the control mice and those treated with phosphate-buffered saline. This delay gradually increased over the treatment sessions to at least $75 \%$ at day 30 . In contrast, complete tumor regression was observed in many of the mice in group IV, and Figure 6 shows the decrease in tumor volume as compared with group I, II, and III. Tumor volumes in this group steadily decreased during the experiments, with at least an $85 \%$ reduction noted at the end of treatment. No tumor regrowth was observed following complete regression over a period of 30 days. Magnetic resonance imaging showed tumor regression in many of the mice treated with core shells, and finally complete disappearance of $50 \%$ of the tumors, as shown in 
Table I Mean value of tumor volume growth of the four groups after 30 days

\begin{tabular}{|c|c|c|c|c|}
\hline $\begin{array}{l}\text { Group treatment } \\
\text { days }\end{array}$ & $\begin{array}{l}\text { (I) Control } \\
\mathrm{n}=25 \mathrm{~mm}^{3}\end{array}$ & $\begin{array}{l}\text { (II) Laser@PBS } \\
\mathrm{n}=25 \mathrm{~mm}^{3}\end{array}$ & $\begin{array}{l}\text { (III) Laser@Au-NPs } \\
\mathrm{n}=25 \mathrm{~mm}^{3}\end{array}$ & $\begin{array}{l}\text { (IV) AMF and laser@ } \\
\text { core shell } \\
n=25 \mathrm{~mm}^{3}\end{array}$ \\
\hline After 5 days & $88.8 \pm 1.3$ & $86.5 \pm 1.2$ & $86.2 \pm 0.8$ & $71.5 \pm 0.8$ \\
\hline 10 days & $115.2 \pm 3.8$ & $99.7 \pm 2.6$ & $92.5 \pm 1.6$ & $62.2 \pm 3.6$ \\
\hline 15 days & $130.7 \pm 6.2$ & $118.4 \pm 4.1$ & $105.1 \pm 2.9$ & $48.9 \pm 2.4$ \\
\hline 20 days & $155.3 \pm 10.7$ & $129.8 \pm 7.2$ & $117.8 \pm 3.7$ & $40 \pm 5.3$ \\
\hline 25 days & $168.4 \pm 13.5$ & $147.9 \pm 9.8$ & $126.5 \pm 5.4$ & $34.9 \pm 9.8$ \\
\hline 30 days & $179.8 \pm 15.9$ & $161.5 \pm 12.3$ & $135.9 \pm 6.1$ & $20.6 \pm 8.4$ \\
\hline
\end{tabular}

Abbreviations: PBS, phosphate buffer saline; Au-NPs, gold nanospheres; n, number of mice in each group; AMF, alternative magnetic field.

Figure $7 \mathrm{~A}$ and $\mathrm{B}$, with a concomitant decrease in signal intensity in the regions of interest. The greatest relative decrease in signal intensity was observed after core shell injection, where the change was $26.8 \%$ and continued to a signal loss of $64.9 \%$, with a complete loss of signal at the end of the treatment.

\section{Necrosis}

Statistical analysis revealed a mean area of necrosis of $15.3 \% \pm 2.5 \%$ in group I (controls), $21.1 \% \pm 2.0 \%$ in group II (phosphate-buffered saline), $65.7 \% \pm 1.8 \%$ in group III (gold nanospheres), and $85.9 \% \pm 1.3 \%$ in group IV (core shell nanoparticles, Figure 8).

\section{Survival times}

Survival at the start of treatment was $100 \%$ in all four treatment groups. At 10 days after the start of treatment, group I (controls) and group II (phosphate-buffered saline) mice showed 80\% survival, while group III (gold nanospheres) and group IV (core shell nanoparticles) mice showed survival rates of $90 \%$ and $95 \%$, respectively. At 20 days, survival in group I was $60 \%, 70 \%$ in group II, $85 \%$ in group III, and $90 \%$ in group IV. At 30 days, survival was $50 \%$ in group I, $60 \%$ in group II, $75 \%$ in group III, and $80 \%$ in group IV. At
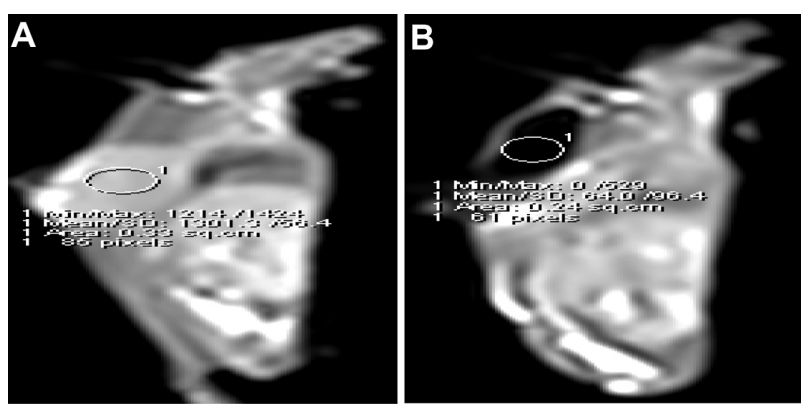

Figure 7 Sagittal TIWI MR images before and after core shell treatment. (A and B) The images revealed loss of signal intensities and complete disappearance of the tumor at the end of the treatment after subjecting to green, NIR, and AMF.

Abbreviations: TIWI, TI weighted images; MR, magnetic resonance; NIR, nearinfrared; AMF, alternative magnetic field.
40 days, survival was $20 \%$ in group I, $35 \%$ in group II, $55 \%$ in group III, and $60 \%$ in group IV. At 50 days, survival was $0 \%$ in group I, $10 \%$ in group II, $50 \%$ in group III, and $55 \%$ in group IV. At 60 days, survival was $0 \%$ in both group I and group II mice, $40 \%$ in group III, and $45 \%$ in group IV. At 70 days, survival was $40 \%$ in group III and $35 \%$ in group IV. After that, only $10 \%$ of mice in group IV were still alive until the last day of follow-up (Figure 9).

\section{Discussion}

Ultraviolet-visible absorption spectroscopy is the most widely used method for characterizing the optical properties of nanospheres. In our study, the core shell nanospheres were slightly red-shifted in surface plasmon resonance wavelength, as shown in Figure 2B. This may be attributable to the larger dimensions of the core shell nanoparticles compared with gold nanospheres, as seen in the transmission electron microscopic images. It is worthy of note that the surface plasmon resonance absorption peak of the gold-iron oxide colloid appeared at about $537 \mathrm{~nm}$. This is attributed to the magnetic optical resonance phenomenon, because it is well

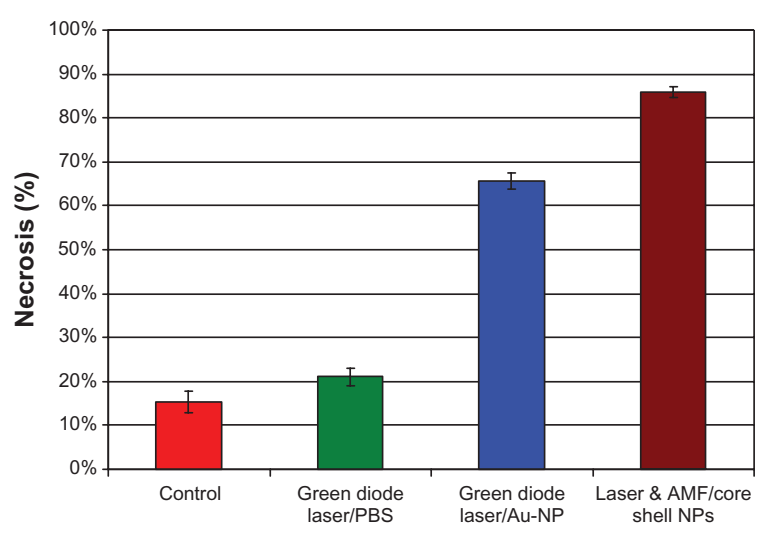

Figure 8 Results of assessment of necrosis in EAC, indicating a significant difference $P<0.05$.

Note: Values indicate the mean percentage of necrosis and standard deviations. Abbreviations: EAC, Ehrlich ascites carcinoma; PBS, phosphate buffer saline; AuNP, gold nanospheres; AMF, alternative magnetic field; NP, nanoparticles. 


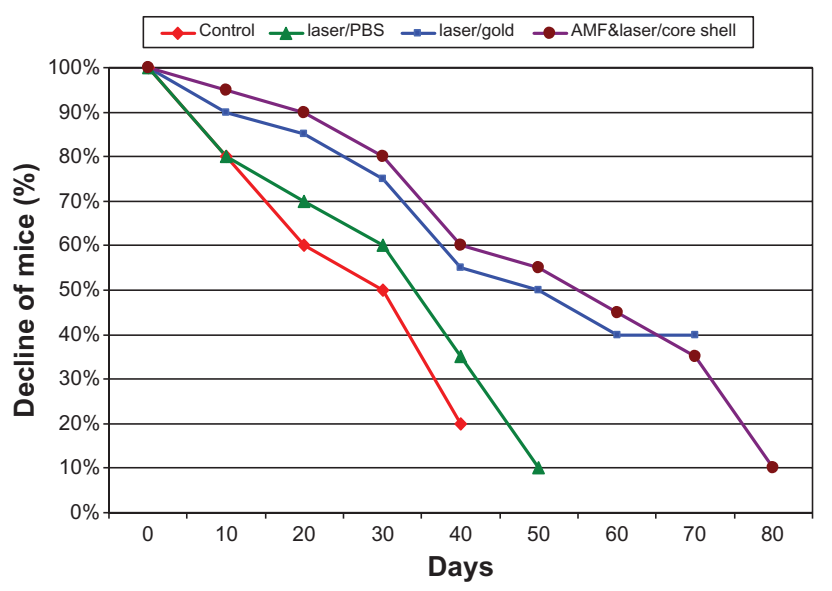

Figure 9 Mice decline in number along the treatment and follow-up period of the control, PBS, gold nanospheres, and core-shell nanoparticles groups.

Abbreviations: PBS, phosphate buffer saline; AMF, alternative magnetic field.

known that iron oxide particles have no specific absorption peak in this region and that the surface plasmon resonance of gold is approximately $520-530 \mathrm{~nm}$. This phenomenon is thought to be the result of overlap between the plasmonic and magnetic resonances of the gold shell and the core iron oxide, respectively. However, the nature of this overlap remains ambiguous and studies which demonstrate this phenomenon are still quite rare.

Our X-ray diffraction results show that the characteristic peaks of the gold-iron oxide nanospheres were similar to those of the pure iron oxide nanospheres (see Figure 3), indicating that the shape of the core determines the shape of the core shell structure. Also, the X-ray diffraction spectrum revealed diffraction peaks of gold that may be attributed to overlap of gold and iron oxide. This is considered to be evidence that the iron magnetic cores are well protected by the gold shell.

The interstitial temperature measurements obtained during each laser treatment method for the 25 mice each in group II, group III, and group IV are described. These temperature measurements are a surrogate for the temperature reached within the tumor cells. As shown in Figure 4, rapid heating was observed upon laser exposure, followed by a steady-state equilibrium. It was noted that more than $90 \%$ of the observed temperature increase occurred within the first 3 minutes. The mean temperature of the core shells was significantly $(P<0.001)$ higher than that of the gold nanospheres and the phosphate buffer system, and hence the maximum temperature was achieved by the core shell nanoparticles, and with the shortest time taken to reach maximum temperature. This is attributed to irradiation by green visible and near infrared laser light at the same time. After switching off the laser, the tissues showed cooling behavior, as expected. It is worth mentioning that the temperature perturbation induced inside the tumor was mainly due to interaction between the accumulated nanospheres and laser as well as radiofrequency. In fact, determination of the spatial distribution of temperature with different depths and concentrations of nanoparticles in biological tissue is one of the most commonly encountered obstacles in this type of research and remains a complicated issue. This problem is due to the geometry of tumors that are often irregularly shaped in both area and depth.

Use of transmission electron microscopy is very important for characterizing particle uptake and distribution into phagosomes or lysosomes in the cytoplasm. Transmission electron micrographs revealed some aggregation of the injected core shell nanospheres, as shown in Figure 5B, which may have been formed during preparation for electron microscopy. There is evidence that the injected nanospheres penetrated the cell membrane and accumulated in the cytoplasmic vesicles, as shown in Figure 5C. Good transmission electron microscopy pictures (Figure 5E and $\mathrm{F}$ ) revealed a high response to the nanocomposite treatment technique.

The dramatic changes in tumor growth seen in Figure 6 are due to variation in hyperthermic effects which, in turn, depend on the heating efficiency of laser irradiation in the treated tissues of the groups that received phosphate-buffered saline or gold nanospheres compared with controls. The higher therapeutic efficacy of the core shell nanocomposites in group IV compared with the delay in growth rate in response to treatment with gold nanospheres in group III may be attributed to homogenous heat distribution throughout the surface area of the tumor enclosed in the periphery of the tumor by applying green diode laser, as well as interstitial heating by near infrared and radiofrequency, both of which had a high penetration depth, whereas the penetration of green diode laser in group III was not enough to penetrate the entire tumor depth. Nanocomposites were more efficient than the individual gold nanospheres, in that the former have optical interactions with near infrared laser, represented in the gold shell, as well as magnetic interactions with radiofrequency, represented in the magnetic core, whereas the gold nanospheres only have optical interactions with the green diode laser. Therefore, the effect on cancer cells was more strongly reflected in disappearance of the tumor, and evident in Figure 7.

The cell death mechanism is temperature-dependent. In our study, the temperature reached was sufficient to induce necrosis, and is confirmed in the transmission electron microscopic images. The quantitative assay of necrosis is shown in Figure 8, and reveals that the extent of necrosis was 
significantly higher in group IV than in group III $(P<0.05)$, and was almost nonexistent in group I and group II. The effect of hyperthermia on the cell death mechanism is still under investigation. Researchers in this field have offered various explanations for these effects. Huff et $\mathrm{al}^{20}$ state that, due to their rapid metabolic rates, tumor cells are regarded as increasingly vulnerable to hyperthermic effects, such as disruption of metabolic signaling processes, protein denaturation, and the onset of acidosis or apoptosis caused by the production of heat shock proteins. On the other hand, Hildebrandt et $\mathrm{al}^{21}$ state that small increases in local temperature result in disruption of nuclear and cytoskeletal assemblies. A recent report by Tong et $\mathrm{a}^{22}$ indicates that there is significant membrane blebbing under hyperthermic conditions. However, in severe conditions, the effects of hyperthermia result in irreversible damage to tumor cells, which indeed was achieved in group IV mice in our study.

The survival rates shown in Figure 9 are in agreement with the microscopic results for tumor responses to the different treatment schedules. Group IV mice showed the best survival rate of $60 \%$ in the first 10 days after the end of the treatment compared with $55 \%$ in group III. At the end of the follow-up period, survival was about $10 \%$ in group IV mice, whereas all the mice in group III died. In general, the shortest survival was in the group I mice and longest in group IV mice.

There are two main advantages of the plasmonic photothermal therapy technique. Firstly, there is the benefit of photostability compared with the photosensitizer dyes used in photodynamic therapy, which suffer from photobleaching as well as diffusion under laser irradiation. Secondly, there is the advantage of absorption and scattering cross-sections of gold nanoparticles, which are significantly superior to the absorbing dyes conventionally used in biological systems. Mie theory estimates that the optical cross-sections of gold nanospheres are typically four to five orders of magnitude higher than those of conventional dyes.

In spite of much progress having been made using the plasmonic photothermal therapy technique for cancer treatment in a laboratory setting, there are still many factors which must be taken into account before this method may be taken to a clinical setting, and they need to be studied further. First of all, the distribution of the elevated temperature under plasmonic photothermal therapy treatment is related to absorption of light by nanospheres acting as point wise local heat sources and by thermal diffusion over surrounding tissues. At the practical level, plasmonic photothermal therapy needs to provide an appropriate temperature increment, $\Delta \mathrm{T}$, gold nanosphere concentration, laser power density, duration of laser exposure, optimization of absorption and scattering cross-sections of nanospheres, as well as penetration of the laser light into the area of interest. It should be noted that the biological effects have a nonlinear dependence on changes in particle concentration and laser power density, which is defined by the type of tissue and thermoregulation ability of the living organism.

\section{Conclusion}

The current study investigated two approaches to the application of photothermal therapy. Photothermolysis of subcutaneous tumors was studied in vivo by local injection of gold nanospheres and nanocomposites into tumor tissue. We have demonstrated that a pair of synthetic nanospheres can work together more effectively for inducing hyperthermia than individual nanospheres, whereby more than $50 \%$ of nanocomposite-treated mice showed complete tumor regression.

\section{Acknowledgments}

We gratefully acknowledge the financial support of the National Institute of Laser, Cairo University, and the Children's Cancer Hospital in this research.

\section{Disclosure}

The authors report no conflicts of interest in this work.

\section{References}

1. Muller G, Roggan A. Laser-Induced Interstitial Thermotherapy. Bellingham, WA: SPIE Press; 1995.

2. Wust P, Hildebrandt B, Sreenivasa G, et al. Hyperthermia in combined treatment of cancer. Lancet Oncol. 2002;3:487-497.

3. Tuchin VV. Tissue Optics: Light Scattering Methods and Instruments for Medical Diagnosis. 2nd ed. Bellingham, WA: SPIE Press; 2007.

4. Ito AB, Tanaka KL, Kondo KN, Shinkai MM, Honda H, Kobayashi T. Tumor regression by combined immunotherapy and hyperthermia using magnetic nanoparticles in an experimental subcutaneous murine melanoma. Cancer Sci. 2003;94:308-313.

5. Kasili PM, Dinh TV. Photothermal treatment of human carcinoma cells using liposome-encapsulated gold nanoshells. Nanobiotechnology. 2005; $1: 245-252$.

6. Maksimova IL, Akchurin GG, Khlebtsov BN, Terentyuk GS. Nearinfrared laser photothermal therapy of cancer by using gold nanoparticles computer simulations and experiment. Med Laser Appl. 2007;22: 199-206.

7. Dickerson EB, Dreaden EC, Huang X, et al. Gold nanorods assisted near-infrared plasmonic photothermal therapy PPTT of squamous cell carcinoma in mice. Cancer Lett. 2008;269:57-66.

8. Chen J, Wang D, Xi J, et al. Immuno gold nanocages with tailored optical properties for targeted photothermal destruction of cancer cells. Nano Lett. 2007;7:1318-1322.

9. Pissuwan D, Valenzuela SM, Cortie MB. Therapeutic possibilities of plasmonically heated gold nanoparticles. Trends Biotechnol. 2006;24:62-67.

10. Visaria R, Bischof JC, Loren M, et al. Nanotherapeutics for enhancing thermal therapy of cancer. Int J Hyperthermia. 2007;23:501-511. 
11. Huang X, Jain PK, El-Sayed IH, El-Sayed MA. Plasmonic photothermal therapy PPTT using gold nanoparticles. Lasers Med Sci. 2008:23:217-228.

12. Hirsch LR, Gobin AM, Lowery AR, et al. Metal nanoshells. Ann Biomed Eng. 2006;34:15-22.

13. Liu VG, Cowan TM, Jeong SW, Jacques SL, Lemley EC, Chen WR. Selective photothermal interaction using an $805-\mathrm{nm}$ diode laser and indocyanine green in gel phantom and chicken breast tissue. Lasers Med Sci. 2002;17:272-279.

14. Gobin AM, Lee MH, Halas NJ, James WD, Drezek RA, West JL. Near-infrared resonant nanoshells for combined optical imaging and photothermal cancer therapy. Nano Lett. 2007;7:1929-1934.

15. Loo C, Lowery A, Halas N, West J, Drezek R. Immunotargeted nanoshells for integrated cancer imaging and therapy. Nano Lett. 2005;5:709-711.

16. Yang WL, Nair DG, Makizumi R, et al. Heat shock protein 70 is induced in mouse human colon tumor xenografts after sublethal radiofrequency ablation. Ann Surg Oncol. 2004;11:399-406.

17. Hirsch LR, Stafford RJ, Bankson JA, et al. Nanoshell-mediated nearinfrared thermal therapy of tumors under magnetic resonance guidance. Proc Natl Acad Sci U S A. 2003;100:13549-13554.
18. Diagaradjane PN, Shetty AS, Wang JK, Elliot AL, Schwartz JS, Krishnan S. Modulation of in vivo tumor radiation response via gold nanoshell-mediated vascular-focused hyperthermia: Characterizing an integrated antihypoxic and localized vascular disrupting targeting strategy. Nano Lett. 2008;8:1492-1500.

19. El-Sherbini AA, Mahmoud SA, Mohamed AA, Ahmed AW, Hesham AS. Magnetic nanoparticles-induced hyperthermia treatment under magnetic resonance imaging. J Magn Reson Imaging. 2011;29: 272-280.

20. Huff MT, Tong YN, Zhao LM, Hansen JW, Cheng KX, Wei AA. Hyperthermic effects of gold nanorods on tumor cells. Nanomedicine. 2007;2:125-132.

21. Hildebrandt BA, Wust BP, Ahlers AO, et al. The cellular and molecular basis of hyperthermia. Crit Rev Oncol Hematol. 2002;43:33-56.

22. Tong LN, Zhao YY, Huff TJ, Hansen MK, Wei A, Cheng J. Gold nanorods mediate tumor cell death by compromising membrane integrity. JAdv Mater. 2007;19:3136-3141. 


\section{Supplementary figures}
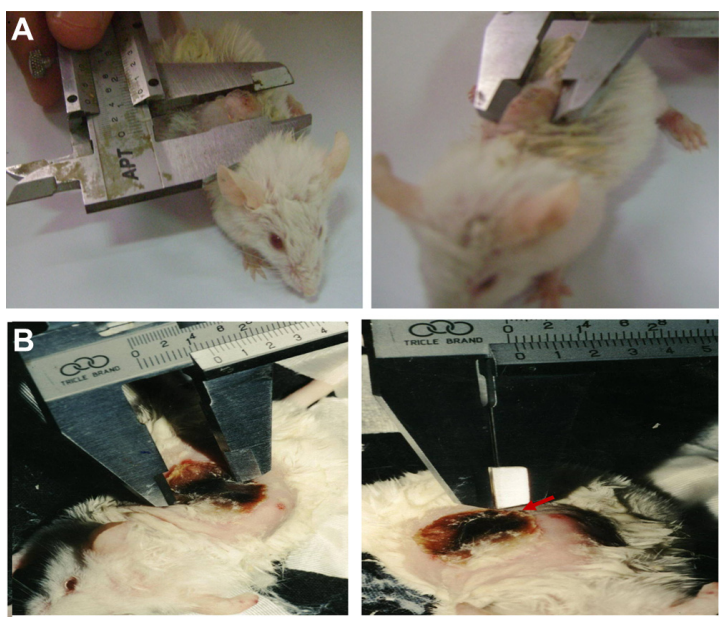

Figure SI (A) Photographs showing measurement of tumor size in mice by a caliper in two dimensions, ie, vertical and horizontal. (B) Core shell-treated mouse with morphological changes appearing on the tumor surface after being subjected to green diode laser and interstitial near infrared at the same time followed by AMF. Red arrow refers to reduction of height dimension. Abbreviation: AMF, alternative magnetic field.
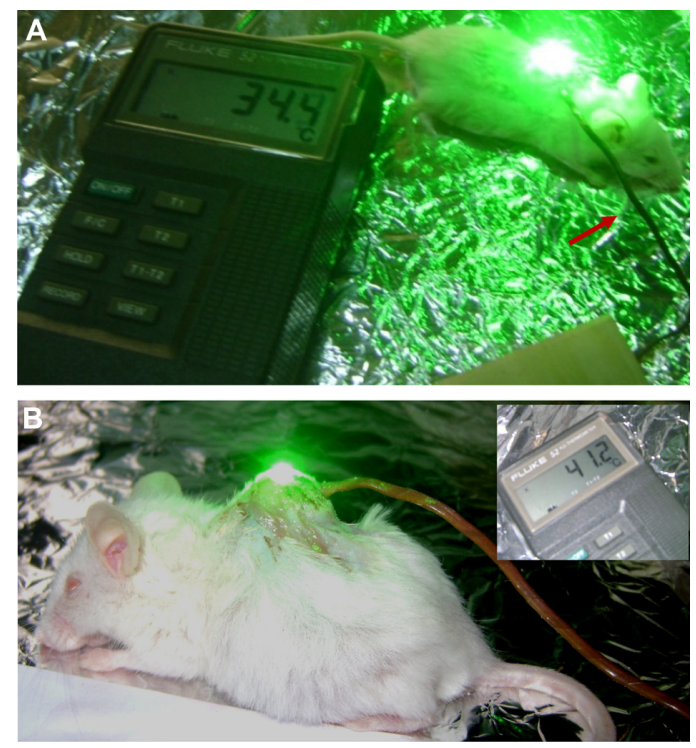

Figure S2 (A) Photograph of mouse with subcutaneous Ehrlich carcinoma tumor injected with colloidal gold nanosphere solution, and subjected to green diode laser. An interstitial probe was inserted into the tumor for measuring interstitia temperature (red arrow). The digital thermometer reading was $34.4^{\circ} \mathrm{C}$ within the first 2 minutes of exposure. (B) Photograph of mouse with subcutaneous Ehrlich carcinoma tumor injected with gold nanospheres and subjected to green diode laser. An interstitial probe was inserted into the tumor for measuring temperature. Maximum temperature was achieved after 5 minutes of radiation, as shown in inset.

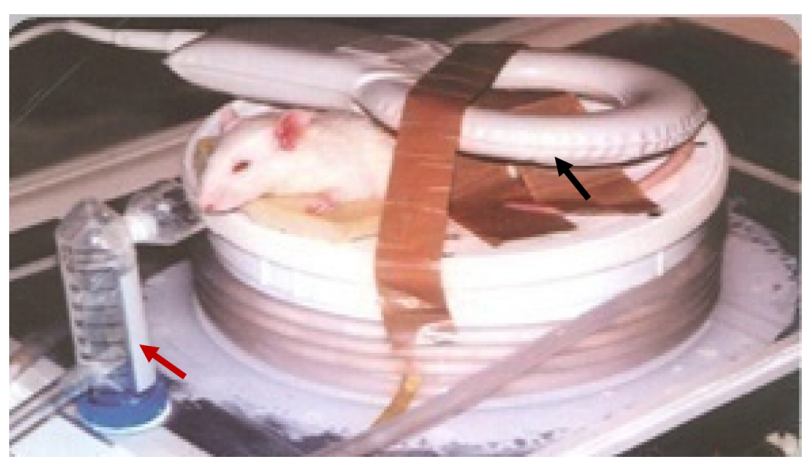

Figure S3 Typical photograph of mouse under magnetic resonance imaging. Red arrow refers to the anesthesia system, black arrow refers to radiofrequency coil.
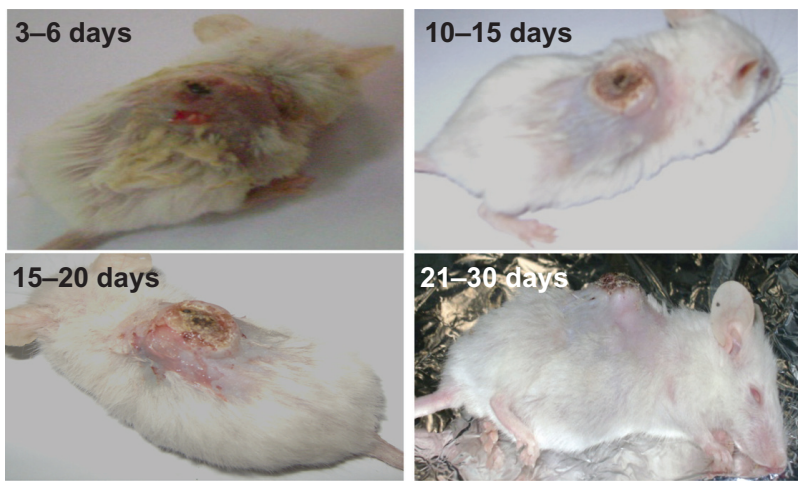

Figure S4 Morphological changes on tumor surface on different treatment days after being exposed to green diode laser and gold nanospheres.
International Journal of Nanomedicine

\section{Publish your work in this journal}

The International Journal of Nanomedicine is an international, peerreviewed journal focusing on the application of nanotechnology in diagnostics, therapeutics, and drug delivery systems throughout the biomedical field. This journal is indexed on PubMed Central, MedLine, CAS, SciSearch ${ }^{\circledR}$, Current Contents ${ }^{\circledR} /$ Clinical Medicine,

\section{Dovepress}

Journal Citation Reports/Science Edition, EMBase, Scopus and the Elsevier Bibliographic databases. The manuscript management system is completely online and includes a very quick and fair peer-review system, which is all easy to use. Visit http://www.dovepress.com/ testimonials.php to read real quotes from published authors.

Submit your manuscript here: http://www.dovepress.com/international-journal-of-nanomedicine-journal 